\title{
EXTRAÇÃO SELETIVA DE METAIS PESADOS EM SEDIMENTOS DE FUNDO DO RIO TIETÊ, SÃO PAULO
}

\author{
José Eduardo Bevilacqua \\ Cia de Tecnologia e Saneamento Ambiental do Estado de São Paulo, São Paulo - SP, Brasil \\ Ivone Silveira da Silva* \\ Departamento de Ciências Exatas e da Terra, Universidade Federal de São Paulo, Rua Artur Riedel, 275, 09972-270 Diadema - \\ SP, Brasil \\ Jaim Lichtig e Jorge César Masini \\ Instituto de Química, Universidade de São Paulo, CP 26077, 05513-970 São Paulo - SP, Brasil
}

Recebido em 24/10/07; aceito em 13/8/08; publicado na web em 20/1/09

\begin{abstract}
SELECTIVE EXTRACTION OF HEAVY METALS IN BOTTOM SEDIMENTS FROM TIETÊ RIVER, SÃO PAULO. Sediment samples from Tietê river were submitted to chemical and sequential extractions of heavy metals $(\mathrm{Cd}, \mathrm{Cr}, \mathrm{Cu}, \mathrm{Ni}, \mathrm{Pb}$ and $\mathrm{Zn})$. It was followed a single extraction by using $0.1 \mathrm{~mol} \mathrm{~L}^{-1}$ hydrochloric acid and a sequential procedure to evaluate possible chemical associations described as exchangeable, carbonate, reducible oxides, sulfide, organic matter and residual fractions. High concentrations of heavy metals were determined at Pirapora reservoir, which is closer to the Metropolitan Area of São Paulo while for Barra Bonita reservoir, the results showed low concentrations for such elements. Acid volatile sulfides, grain size distribution and carbon contents were also determined.
\end{abstract}

Keywords: heavy metals; sediment; chemical and sequential extractions.

\section{INTRODUÇÃO}

Há pelo menos 3 décadas, os sedimentos já não têm sido considerados somente ambientes de deposição de espécies químicas, mas um compartimento aquático ativo que desempenha um papel fundamental na redistribuição dessas espécies à biota aquática. ${ }^{1} \mathrm{Os}$ processos naturais de formação de sedimentos vêm sendo intensamente alterados pela ação do homem. A erosão do solo causada pela construção de prédios e rodovias, bem como o lançamento direto de efluentes industriais e municipais têm propiciado um perfil significativamente diferente daqueles verificados em ambientes naturais não impactados. ${ }^{2}$ Nesse contexto, uma atenção especial deve ser dada aos metais pesados, que não são naturalmente degradados, nem mesmo permanentemente fixados pelos sedimentos, podendo assim retornar à coluna d'água através de alterações de suas propriedades físico-químicas, tais como $\mathrm{pH}$ e potencial redox. ${ }^{3}$

Sob condições operacionais definidas, os métodos analíticos de extração seqüencial têm sido aplicados com a proposta de se avaliar a distribuição dos metais nas diferentes formas que compõem o sedimento, tendo em vista o comportamento, a reatividade e o destino dessas espécies nos ambientes aquáticos. ${ }^{3}$

Os métodos de extração seqüencial consistem em submeter uma determinada amostra de sedimento sob condições de extração em etapas cada vez mais enérgicas (tipos de reagentes, concentração, tempo e temperatura). As frações obtidas dizem respeito à proporção do metal que está associada a uma referida fase geoquímica. .Kersten e Förstner ${ }^{4,5}$ desenvolveram um método de extração seqüencial que foi aplicado num estudo dos sedimentos do Rio Elba, altamente impactados, cujas frações foram definidas como trocáveis, metais ligados a carbonatos, metais associados aos óxidos facilmente redutíveis, metais associados aos óxidos moderadamente redutíveis e residual.

Alguns problemas têm sido apontados aos métodos de extração seqüencial, tais como possíveis redistribuições do metal entre fases,

*e-mail: is.silva@unifesp.br seletividade dos reagentes, além da falta de concordância entre os resultados, principalmente para sedimentos anóxidos. ${ }^{5,6}$ Embora os métodos de extração apresentados na literatura devam ser devidamente melhorados, ainda são a única forma de se avaliar a distribuição dos metais entre as fases geoquímicas que compõem o sedimento. ${ }^{7}$

O método de extração seqüencial de metais adotado neste trabalho de pesquisa compreendeu as seguintes etapas: ${ }^{4,5}$ Fração trocável - a dupla camada elétrica estabelecida na superfície do sedimento é controlada principalmente pelo $\mathrm{pH}$ da superfície e pela força iônica do meio. Dessa forma, sais neutros, como $\mathrm{MgCl}_{2}, \mathrm{NaNO}_{3}$ ou mesmo $\mathrm{NH}_{4} \mathrm{Oac}$, são comumente escolhidos para extrair metais, por deslocamento dos sítios de adsorção. Um estudo sistemático sobre a eficiência de certos sais na extração de metais mostrou que $\mathrm{NH}_{4} \mathrm{OAc}$ foi totalmente eficiente na extração de $\mathrm{Zn}, \mathrm{Cu}$ e $\mathrm{Mn}$, enquanto que os outros apresentaram resultados sensivelmente menores; ${ }^{8} \underline{\text { Fração }}$ ligada a carbonatos - o uso de tampão acetato tem sido incorporado em praticamente todos os esquemas de extração. Apesar da eficiência de extração verificada nos experimentos, são encontrados também elevados níveis de ferro e manganês nas soluções. Esses efeitos são, segundo estes autores, estritamente dependentes da preservação das condições redox durante o procedimento analítico, devido à reatividade das fases Fe/Mn (II), o que sugere um controle rigoroso nesta etapa de extração; ${ }^{8}$ Fração de metais associados aos óxidos facilmente redutíveis - esta fração se justifica para que haja uma diferenciação entre óxidos cristalinos de Fe/Mn e oxidratos não cristalinos. Nesse sentido, uma extração com ênfase na fração de óxidos facilmente redutíveis esclarece satisfatoriamente o grau de associação dos metais com esta fase; Fração de metais associados aos óxidos moderadamente redutíveis - esta etapa é utilizada há muitos anos nos estudos de caracterização da cristalinidade de óxidos de ferro e alumínio, importante parâmetro de classificação de solos. Tal extração baseia-se no princípio que os óxidos amorfos de ferro sofrem ataque completo por uma solução de ácido oxálico 0,1 M tamponada com oxalato de amônio (para pH 3), com agitação e ausência de luz. Na ausência do efeito catalítico da luz, esse reagente não dissolve óxidos de ferro 
cristalinos ${ }^{8}$ Fração de sulfetos e matéria orgânica - nesta etapa podese avaliar a distribuição dos metais em função das suas afinidades por sulfetos ou matéria orgânica, através de um ataque químico aos componentes oxidáveis dos sedimentos; Fração residual - esta fração não é considerada importante nos processos de transformações diagenéticas recentes, mas possibilita realizar-se o balanço final dos metais na extração.

Outra forma de se avaliar a mobilidade dos metais diz respeito às extrações com ácido a frio, que simulam processos de remoção desses metais dos sedimentos mais "reativos". Esta abordagem é particularmente interessante quando o ambiente se encontra fortemente impactado. ${ }^{9,10}$ Tais ensaios vêm sendo utilizados no diagnóstico de ambientes recém-contaminados e apresentam fortes correlações com estudos de bioacumulação e biodisponibilidade em organismos. ${ }^{11,12}$

Foram realizadas determinações de metais totais presentes em amostras de sedimentos e suas frações definidas por um procedimento de extração seqüencial, segundo o método de Kersten e Förstner. ${ }^{5}$ Adotou-se ainda o método de extração a frio em meio de $\mathrm{HCl} 0,1$ mol L ${ }^{-1}$ para se estimar a fração dos metais lábeis, móveis, ou também considerados potencialmente biodisponíveis ${ }^{11-13}$ ou ainda pode determinar a qualidade de sedimentos. ${ }^{14}$

Este trabalho teve como objetivo avaliar os níveis de concentração de metais pesados e suas possíveis associações em amostras de sedimentos de fundo do Rio Tietê, no trecho compreendido entre o Reservatório de Pirapora até o de Barra Bonita.

Além do estudo dos metais nos sedimentos, outros importantes parâmetros físico-químicos e analíticos foram determinados, tais como potencial redox $\left(\mathrm{E}_{\mathrm{H}}\right), \mathrm{pH}$, sulfeto volatilizável com ácido (SVA), distribuição granulométrica e concentração de frações de carbono.

\section{PARTE EXPERIMENTAL}

\section{Amostragem de sedimentos}

O trecho estudado no Rio Tietê perfaz uma distância de 260 km, entre os reservatórios de Pirapora do Bom Jesus (Região Metropolitana de São Paulo) e Barra Bonita, no interior do estado de São Paulo. Os sedimentos de fundo foram amostrados no período de janeiro de 1993, em 7 pontos, sendo um no Reservatório de Pirapora (canal central mais profundo, a montante da Barragem de Pirapora), um no Reservatório de Rasgão (a montante da Usina de Rasgão), um no Reservatório de Tecelagem, um sob a ponte Tietê-Capivari e três no Reservatório de Barra Bonita (pontos locados a montante, no trecho intermediário e a jusante do reservatório). ${ }^{15}$

As amostras de sedimentos foram coletadas utilizando-se uma draga do tipo Eckman, na qual foram obtidas amostras, que foram transferidas diretamente para frascos de polietileno de boca larga, evitando-se contato com o ar. Estes foram preenchidos completamente, evitando-se a presença de bolhas de ar. Os frascos foram dispostos em caixa de isopor contendo gelo e, posteriormente, em laboratório, foram mantidos sob refrigeração a $4{ }^{\circ} \mathrm{C}$ e ausência de luz, sendo envolvidos com papel alumínio.

As medidas iniciais de $\mathrm{pH}$ e $\mathrm{E}_{\mathrm{H}}$ foram realizadas em laboratório, assim que os frascos foram retirados das caixas de isopor. As medidas de $\mathrm{E}_{\mathrm{H}}$ foram feitas com um eletrodo de anel de platina (Ingold), um eletrodo de referência $\mathrm{Ag} / \mathrm{AgCl}$ Xerolyt (Ingold) e um potenciômetro Micronal modelo B-375 ( $\pm 0,1 \mathrm{mV})$. Os valores de $\mathrm{E}_{\mathrm{H}}$ foram referendados em relação ao valor apresentado por uma solução padrão descrita por ZoBell. ${ }^{16}$

$\mathrm{Na}$ realização das leituras de $\mathrm{E}_{\mathrm{H}}$, os eletrodos foram introduzidos em cerca de $5 \mathrm{~cm}$ no interior da amostra contida no frasco de coleta, em ambiente de nitrogênio, a fim de se evitar qualquer contato da amostra com o ar, sendo que a boca do frasco foi previamente coberta com um filme de PVC. Foram verificados valores estáveis de potencial em um intervalo de tempo de 5 a 10 min.

As leituras de $\mathrm{pH}$ foram realizadas de forma semelhante às de $\mathrm{E}_{\mathrm{H}}$, introduzindo-se diretamente nas amostras um eletrodo de vidro combinado de $\mathrm{pH}$ (Ingold, modelo Argenthal). As leituras de $\mathrm{pH}$ foram muito mais rápidas que as de $\mathrm{E}_{\mathrm{H}}$, requerendo-se um tempo para estabilização de somente $30 \mathrm{~s}$. As amostras foram mantidas em refrigerador, e, mensalmente, foram realizadas medidas de $\mathrm{E}_{\mathrm{H}}$ e $\mathrm{pH}$ durante um período de 3 anos.

\section{Extração seqüencial de metais}

A distribuição de metais pesados nas diversas fases que compõem os sedimentos amostrados no Rio Tietê foi avaliada segundo o método de extração seqüencial proposto por Kersten e Förstner. ${ }^{8}$ Este procedimento preconiza a manutenção de condições anóxidas durante a extração e, conseqüentemente, a sua integridade anaeróbica. Esta proposta se enquadra adequadamente no estudo dos sedimentos do Rio Tietê, que apresenta condições anóxidas nos trechos mais críticos de contaminação. Estes autores têm demonstrado que as frações lábeis apresentarão resultados mais elevados caso a extração de amostras anóxidas seja conduzida ao ar livre, não condizendo com a situação real do ambiente.

As amostras de sedimentos foram pesadas em uma balança analítica no interior de um glove-bag (atmosbag®, Aldrich), sob pressão levemente positiva de $\mathrm{N}_{2}$. Aplicaram-se pelo menos 3 cargas de gás até a expulsão do ar remanescente. Foram utilizados frascos de Pirex Schoot $(80 \mathrm{~mL})$, com tampa rosqueável e batoque interno, a fim de evitar contato das amostras com o ar. Para cada amostra, foi retirada uma alíquota $(5,0$ a $10,0 \mathrm{~g})$ do centro do respectivo frasco com auxílio de uma colher de plástico, que foi submetida às etapas de extração seqüencial. Procurou-se manter uma proporção entre volume do reagente de extração e da massa seca de sedimento em torno de 20:1.

O método de extração seqüencial adotado neste trabalho de pesquisa compreende seis etapas, cujos procedimentos analíticos foram realizados conforme descrição das etapas apresentadas a seguir:

1) Fração trocável - a alíquota da amostra do sedimento anóxido foi dividida em duas partes, sendo que a metade foi conduzida para uma estufa a vácuo a fim de se determinar o conteúdo sólido ou teor de umidade do sedimento (em triplicata), e a outra metade foi destinada para o recipiente de extração no interior de um glove-box. Adicionou-se em seguida $50 \mathrm{~mL}$ de $\mathrm{NH}_{4} \mathrm{OAc}$ com $\mathrm{pH}$ ajustado em 7. Esta suspensão foi agitada a $200 \mathrm{rpm}$ por $2 \mathrm{~h}$ num agitador horizontal de cultura de tecidos (New Brunswick), a temperatura ambiente. Após cessar a agitação, deixou-se a solução repousar um tempo suficiente para separação de duas fases. Na seqüência, o frasco foi conduzido para o interior do glove-box, realizando-se a transferência do sobrenadante, para um tubo de centrífuga de polipropileno $(50 \mathrm{~mL})$, com tampa rosqueável. A transferência do líquido foi realizada com o auxílio de uma seringa plástica hipodérmica de $20 \mathrm{~mL}$, afim de reduzir as possíveis perdas de extrato obtido durante esta etapa. O tubo foi retirado da câmara de glove-box e conduzido a uma centrífuga, com rotação de $4000 \mathrm{rpm}$ durante $20 \mathrm{~min}$. Após a centrifugação, o tubo foi conduzido novamente para o interior da câmara e o sobrenadante foi filtrado numa seringa hipodérmica adaptada a uma membrana filtrante $0,45 \mu \mathrm{m}$ (purgado em $\mathrm{N}_{2}$ ) para então ser transferido para um frasco apropriado de polietileno de alta densidade. Cerca de 50 mg de EDTA foram adicionados para prevenir a precipitação de $\mathrm{Fe}$ durante a estocagem deste extrato, que foi mantido sob refrigeração até a determinação de metais;

2) Fração ligada a carbonatos - ao resíduo da fração trocável foram adicionados $50 \mathrm{~mL}$ de uma solução tampão de NaOAc $1 \mathrm{M}$ e HOAc 
(0,001 M). Esta suspensão foi agitada a $200 \mathrm{rpm}$, por um período de $5 \mathrm{~h}$. Os passos de centrifugação, filtração e transferência foram semelhantes aos descritos para a fração anterior, inclusive a adição de EDTA ( $50 \mathrm{mg}$ ) ao extrato obtido nesta etapa;

3) Fração facilmente redutível - o resíduo sólido da etapa anterior foi lavado uma vez com água deionizada e deaerada, a fim de minimizar a ação da solução tampão remanescente. Procedeu-se à extração com $50 \mathrm{~mL}$ de uma solução de $\mathrm{NH}_{2} \mathrm{OH}$. $\mathrm{HCl}\left(0,01 \mathrm{~mol} \mathrm{~L}^{-1}\right)$ em pH 2, durante um período de $12 \mathrm{~h}$. O extrato obtido foi centrifugado, filtrado e transferido para um frasco de polietileno de alta densidade, sendo mantido sob refrigeração;

4) Fração moderadamente redutível - o resíduo da etapa precedente foi extraído com $\mathrm{H}_{2} \mathrm{C}_{2} \mathrm{O}_{4} /\left(\mathrm{NH}_{4}\right)_{2} \mathrm{C}_{2} \mathrm{O}_{4} 0,1 \mathrm{M} \mathrm{em} \mathrm{pH} \mathrm{3,} \mathrm{por} 24 \mathrm{~h}$. Após esta extração, o resíduo foi lavado com água deionizada e deaerada, finalizando-se assim o uso da câmara de atmosfera inerte ou glovebox. O extrato obtido foi centrifugado, filtrado e acondicionado conforme a etapa anterior;

5) Fração de sulfetos e matéria orgânica - a fim de promover um ataque aos componentes oxidáveis do sedimento, o resíduo lavado foi digerido duas vezes com $\mathrm{H}_{2} \mathrm{O}_{2} 30 \%$ em $\mathrm{HNO}_{3} 0,02 \mathrm{M}$, a uma temperatura de $85^{\circ} \mathrm{C}$ até a sua secura. Para se remover os metais associados a esta

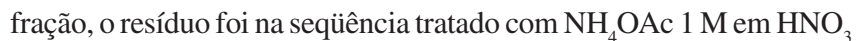
$6 \%$, durante um período de $12 \mathrm{~h}$. O extrato obtido foi centrifugado, filtrado e acondicionado conforme a etapa anterior;

6) Fração residual - ao resíduo da etapa precedente, foram adicionados $10,0 \mathrm{~mL}$ de $\mathrm{HNO}_{3}$, elevando-se a temperatura a $95^{\circ} \mathrm{C}$ em chapa de aquecimento por $2 \mathrm{~h}$ até quase a secura da amostra. O resíduo final foi lavado com água deionizada e a solução obtida foi separada do material sólido por centrifugação, filtrada, acondicionada em frasco de polietileno e mantida sob refrigeração.

O manuseio das amostras durante as quatro etapas iniciais de extração foi conduzido no interior de um glove-box (Labconco) em linha de $\mathrm{N}_{2}$ (grau R, Oxigênio do Brasil). O gás foi purificado com solução de vanádio em amálgama de $\mathrm{Zn}$ e seco com $\mathrm{H}_{2} \mathrm{SO}_{4}$, antes de alimentar a câmara. O procedimento adotado na operação da câmara foi de um vácuo inicial, seguido de alimentação suficiente de $\mathrm{N}_{2}$ até o seu preenchimento. Esta operação foi repetida umas três vezes, até a renovação satisfatória da atmosfera de $\mathrm{N}_{2}$. As soluções de extração $\left(\mathrm{NH}_{4} \mathrm{OAc}, \mathrm{HOAc} / \mathrm{NaOAc}, \mathrm{NH}_{2} \mathrm{OH} . \mathrm{HCl}\right.$ e $\mathrm{H}_{2} \mathrm{C}_{2} \mathrm{O}_{4}$ / $\left.\left(\mathrm{NH}_{4}\right)_{2} \mathrm{C}_{2} \mathrm{O}_{4}\right)$ foram deaeradas durante pelo menos 90 min antes de serem adicionadas às amostras, de acordo com as respectivas etapas de extração.

A determinação dos metais $(\mathrm{Cd}, \mathrm{Cr}, \mathrm{Cu}, \mathrm{Ni}, \mathrm{Pb}$ e $\mathrm{Zn})$ foi realizada por espectrometria de absorção atômica com chama, em um equipamento Perkin-Elmer modelo 3110, com correção de background realizada por lâmpada de deutério. Os limites de detecção e de determinação foram estimados segundo as recomendações sugeridas por Christian. ${ }^{17}$ Os padrões foram preparados com as mesmas soluções de extração, a fim de se minimizarem efeitos de matriz durante as determinações por absorção atômica. Foram verificados efeitos significativos somente na $4^{\text {a }}$ etapa de extração (tampão oxalato) para $\mathrm{Cd}, \mathrm{Ni}, \mathrm{Pb}$ e $\mathrm{Zn}$.

Todos os reagentes utilizados neste trabalho foram de grau de pureza P.A.-ACS e todas as vidrarias e recipientes plásticos foram lavados com detergente Extran 5\%, enxaguados e mantidos em $\mathrm{HNO}_{3}$ $(30 \%)$, por 15 dias e novamente enxaguados somente no instante de serem utilizados. A água utilizada foi de elevada pureza, obtida por um equipamento Millipore, modelo Milli-Q (18,2 M $\Omega / \mathrm{cm})$.

\section{Extração de metais com $\mathrm{HCl} 0,1 \mathrm{~mol} \mathrm{~L}^{-1}$ e abertura total}

No método de extração com $\mathrm{HCl} 0,1 \mathrm{~mol} \mathrm{~L}^{-1}$, secou-se uma quantidade de sedimento a $60{ }^{\circ} \mathrm{C}$, por um período de $96 \mathrm{~h}$ e, em seguida, foi pesada uma massa (cerca de 1,25 g) no interior de um frasco de polietileno $(250 \mathrm{~mL})$, no qual foram adicionados 25,0 $\mathrm{mL}$ de $\mathrm{HCl} 0,1 \mathrm{~mol} \mathrm{~L}^{-1}$. Esta suspensão foi agitada a $200 \mathrm{rpm}$ por um período de $2 \mathrm{~h}$ em um agitador horizontal e a seguir foi mantida em repouso por cerca de $2 \mathrm{~h}$, sendo então filtrada em papel de filtração lenta. $\mathrm{O}$ extrato obtido foi mantido sob refrigeração até a determinação dos metais.

No caso das determinações dos metais totais, utilizou-se como fonte de calor um forno de microondas CEM - 2000. Nesta determinação, uma massa de cerca de $0,5 \mathrm{~g}$ de sedimento seco foi pesada em um tubo de Teflon e em seguida foram adicionados $1,0 \mathrm{~mL}$ de $\mathrm{HCl}, 3,0 \mathrm{~mL}$ de $\mathrm{HNO}_{3}$ e 7,0 mL de HF. A abertura total ocorreu em um tempo de 20 min, a $520 \mathrm{~W}$ de potência, e atingiu-se nestas condições cerca de 95 psi de pressão no sistema. Após o ataque em microondas, as amostras foram tratadas com $\mathrm{H}_{3} \mathrm{BO}_{3}$ sólido para a solubilização de fluoretos como o de $\mathrm{Al}$, bem como a eliminação do $\mathrm{HF}$ remanescente.

A determinação de metais $(\mathrm{Cd}, \mathrm{Cr}, \mathrm{Cu}, \mathrm{Fe}, \mathrm{Mn}, \mathrm{Ni}, \mathrm{Pb}$ e $\mathrm{Zn})$ foi realizada por espectrofotometria de absorção atômica por chama. As curvas dos padrões foram preparadas em meio de $\mathrm{HCl} 1 \%$. Os resultados obtidos foram avaliados aplicando-se o mesmo método analítico de abertura em uma amostra de referência certificada de sedimentos de lago (CANMET-3), na qual se verificou que os resultados foram concordantes ao nível de confiança de $95 \%$ para todos os metais determinados.

\section{Determinação de sulfeto volatilizável com ácido (SVA)}

As amostras destinadas à determinação de SVA foram pesadas em uma balança analítica, a qual foi disposta no interior de um glovebag (atmosbag ${ }^{\circledR}$, Aldrich), sob corrente de $\mathrm{N}_{2}$ e uma leve pressão positiva. Cerca de $0,15 \mathrm{~g}$ de amostra foi pesada no interior de um tubo de vidro previamente tarado. Paralelamente, foram também pesadas algumas alíquotas da mesma amostra para determinação do teor de umidade através da secagem dos sedimentos em estufa a $60{ }^{\circ} \mathrm{C}$ por $96 \mathrm{~h}$ (em triplicata).

$\mathrm{Na}$ Figura 1 é apresentado esquematicamente o sistema que foi utilizado para a obtenção de SVA a partir da amostra de sedimento úmido. Os métodos analíticos utilizados na determinação de SVA utilizam ácidos concentrados $\left(\mathrm{HCl}_{\text {ou }} \mathrm{H}_{2} \mathrm{SO}_{4}\right)$ diretamente na amostra e o produto $\left(\mathrm{H}_{2} \mathrm{~S}\right)$ é arrastado com gás inerte $\left(\mathrm{N}_{2}\right)$, para uma solução absorvedora apropriada para íons $\mathrm{S}^{2-} .^{18}$

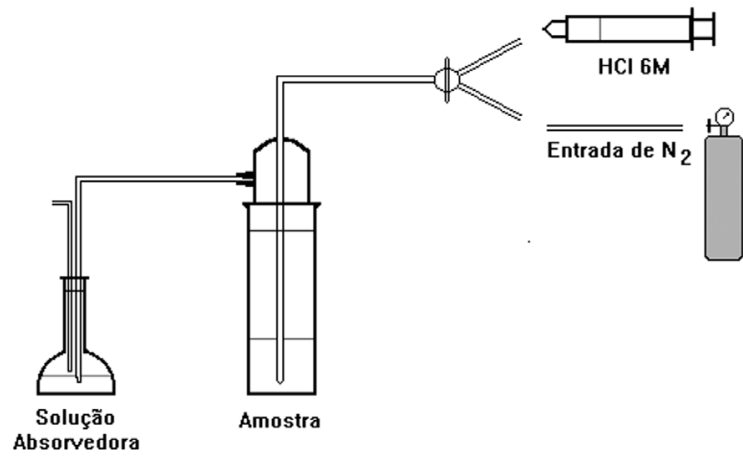

Figura 1. Esquema simplificado do sistema de evolução de SVA

Adaptou-se ao sistema uma seringa plástica com ponta de silicone, com a qual foram adicionados cerca de $15,0 \mathrm{~mL} \mathrm{de} \mathrm{HCl} 6 \mathrm{~mol} \mathrm{~L}^{-1} .^{19}$ $\mathrm{O}$ gás gerado (predominantemente $\mathrm{H}_{2} \mathrm{~S}$ ) foi arrastado com $\mathrm{N}_{2}$ seco, numa vazão de 4 bolhas por segundo, para um balão volumétrico de 
$25 \mathrm{~mL}$ com cerca de $10,0 \mathrm{~mL}$ de uma solução anti-oxidante, composta por EDTA 0,1 M, ácido ascórbico 0,09 M e NaOH 0,6 M. ${ }^{20}$

Através de vários testes, foi verificado que o arraste dos sulfetos volatilizáveis com ácido se completa num tempo de $20 \mathrm{~min}$. As determinações de sulfeto foram realizadas por potenciometria de íonseletivo, utilizando-se um potenciômetro Micronal modelo B-375 ( \pm $0,1 \mathrm{mV}$ ) e um eletrodo íon-seletivo desenvolvido por Serrano. ${ }^{21}$ Este eletrodo consiste de uma membrana de $\mathrm{Ag}_{2} \mathrm{~S}$ (50 mm de espessura), disposta dentro de um tubo de PTFE, sendo que o contato elétrico é dado por um fio de prata. $\mathrm{O}$ sistema de referência foi estabelecido com um eletrodo de $\mathrm{Ag} / \mathrm{AgCl}$, modelo Xerolyt (Ingold), não-contaminável por íons $\mathrm{S}^{2-}$.

O método de curva de calibração levantada diariamente apresentou os melhores resultados, quando comparados aos obtidos pelo método da adição de padrão. A curva analítica mostrou-se linear ( $\mathrm{r}$ $=0,9999 ; \mathrm{n}=4$ ) entre 0,08 e $2,00 \mu \mathrm{g} / \mathrm{mL}$. Observou-se uma recuperação quantitativa superior a $95 \%$, tanto para amostras sintéticas (preparadas com soluções conhecidas) quanto naturais (sedimentos amostrados).

\section{Análise granulométrica}

A análise granulométrica dos sedimentos foi realizada segundo o critério recomendado por Ackermann et al., ${ }^{22}$ que sugerem a utilização de ultrassom durante o peneiramento úmido, a fim de promover uma maior desagregação das partículas.

Inicialmente, as amostras de sedimentos foram secas a $110^{\circ} \mathrm{C}$ por $2 \mathrm{~h}$ e mantidas em um dessecador até a pesagem, sendo que as amostras secas obtidas não foram destorroadas a fim de evitar interferência nos tamanhos dos grãos. Nesta operação foi utilizado um conjunto de peneiras de Teflon, com malha de nylon nas seguintes aberturas 200, 63 e $20 \mu \mathrm{m}$. A peneira de malha correspondente a $200 \mu \mathrm{m}(2 \mathrm{~mm})$ foi utilizada com o intuito de remover todo material de granulação grossa que viesse a interferir na análise, tais como galhos de árvore, folhas, pedregulhos, etc. Após esta pré-seleção dos grãos, a amostra foi pesada diretamente $(10,00 \pm 0,01 \mathrm{~g})$ na peneira previamente tarada $(63 \mu \mathrm{m})$, e esta foi levada para o interior de um frasco plástico de $2 \mathrm{~L}$, preenchido com cerca de $200 \mathrm{~mL}$ de água destilada, que por sua vez foi disposto no interior do banho ultrassônico. O peneiramento foi realizado durante $15 \mathrm{~min}$. O método original faz menção ao uso de pérolas de vidro, a fim de auxiliar no peneiramento, que nos testes realizados não foram necessárias. Após esta operação, a peneira foi parcialmente seca com algumas porções de acetona e em seguida com fluxo de $\mathrm{N}_{2}$. Por último, a peneira foi disposta em um dessecador a vácuo em temperatura de $45{ }^{\circ} \mathrm{C}$ durante várias horas até ser pesada. $\mathrm{O}$ mesmo critério foi adotado para a peneira de $20 \mu \mathrm{m}$.

$\mathrm{O}$ valor da fração $<63 \mu \mathrm{m}$ foi obtido a partir de uma subtração do valor obtido para a fração $<20 \mu \mathrm{m}$. Um total de 3 determinações foram realizadas para cada amostra e o desvios observados não foram superiores a $10 \%$.

\section{Análises de carbono}

As análises de carbono total foram realizadas utilizando-se um analisador elementar (CHN) da Perkin-Elmer. As amostras foram subdivididas em duas porções: uma alíquota (seca e homogênea) foi analisada a fim de se conhecer o conteúdo de carbono total e a outra foi transferida para um frasco de Pirex Schoot $(80 \mathrm{~mL})$, sendo agitada com $\mathrm{HCl} 2 \mathrm{~mol} \mathrm{~L}^{-1}$ por $12 \mathrm{~h}$, a fim de se eliminar carbonatos presentes na amostra de sedimento. A diferença entre os resultados permite conhecer os conteúdos de carbono orgânico e inorgânico na mesma amostra.

\section{RESULTADOS E DISCUSSÃO}

\section{Medições de $\mathbf{p H}$ e potencial redox $\left(\mathrm{E}_{\mathrm{H}}\right)$}

As medições de $\mathrm{pH}$ e $\mathrm{E}_{\mathrm{H}}$ foram realizadas mensalmente por um período de 3 anos, no sentido de avaliar a estabilidade das amostras, quando preservadas sob condições de ausência de luz e calor. Os resultados dessas medições estão ilustrados na Figura 2.
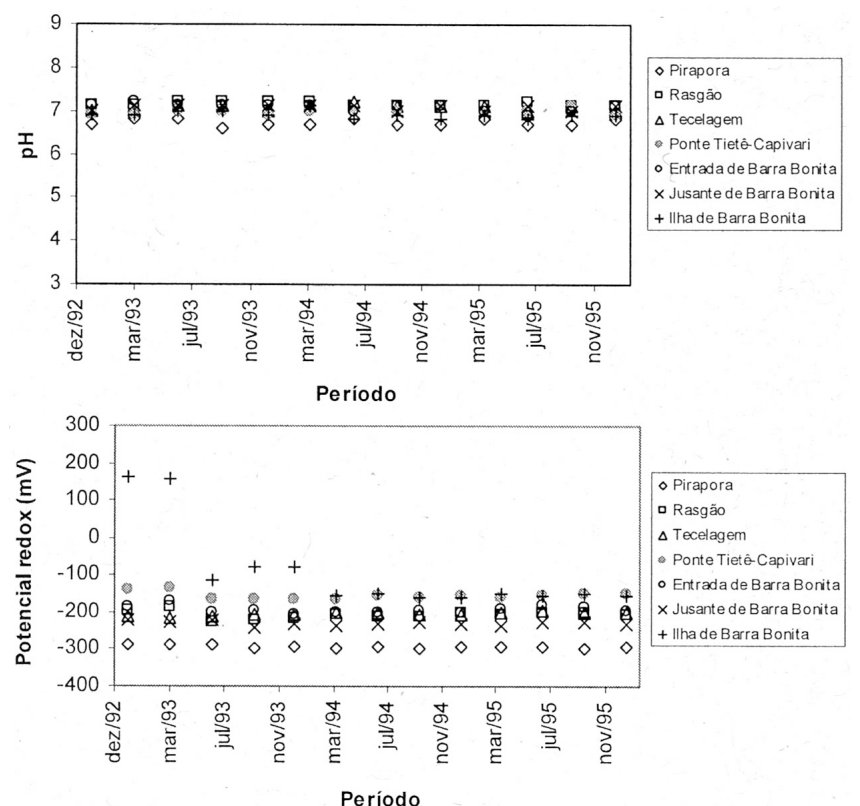

Figura 2. Resultados bimestrais de potencial redox e de $\mathrm{pH}$, no período 1993-1996

Com base nos valores $\mathrm{pH}$ e $\mathrm{E}_{\mathrm{H}}$ obtidos, pode-se dizer que estes reproduzem de modo muito satisfatório as condições originais de amostragem dos sedimentos do Rio Tietê. As amostras que apresentaram baixos valores de $\mathrm{E}_{\mathrm{H}}$ sugerem um nível elevado de estagnação e anaerobiose, caracterizando-se assim um ambiente fortemente impactado por poluição, especialmente de origem orgânica, desde a região metropolitana até a entrada do Reservatório de Barra Bonita.

Os valores constantes de $\mathrm{E}_{\mathrm{H}}$ obtidos para a maioria das amostras podem ser explicados segundo o critério de Wood, ${ }^{23}$ que considera que amostras muito contaminadas podem apresentar certa resistência a mudanças no valor de seu potencial redox, propriedade semelhante à capacidade tampão de um sistema. Isto ocorre principalmente devido à formação de $\mathrm{FeS}$ amorfo nas camadas superiores do sedimento, impedindo assim a livre difusão de $\mathrm{O}_{2}$ na amostra. Além disso, a própria atmosfera de $\mathrm{N}_{2}$ é um fator limitante à oxidação das mesmas.

As variações observadas de $\mathrm{E}_{\mathrm{H}}$ estiveram dentro de um intervalo de 20 a $30 \mathrm{mV}$, que é aceitável em medidas de $\mathrm{E}_{\mathrm{H}}$ realizadas em amostras naturais. Baseando-se nas observações criteriosas de Whitfield, ${ }^{24}$ somente variações superiores a $50 \mathrm{mV}$ sugerem a ocorrência de mudanças irreversíveis nas condições originais de $\mathrm{E}_{\mathrm{H}}$. $\mathrm{O}$ único caso que apresentou uma significativa variação foi aquele verificado para a amostra de Barra Bonita (identificada como ilha - margem esquerda), que no início do estudo (fevereiro/1993) apresentava um valor de $+163 \mathrm{mV}$, correspondente ao de uma amostra óxida, mas que em julho do mesmo ano foi para $-115 \mathrm{mV}$, permanecendo nessa nova condição (anóxida) ao longo dos 18 meses. Esse fenômeno foi explicado por Kersten e Förstner ${ }^{8}$ como sendo uma indução anóxida, causada pela atmosfera de $\mathrm{N}_{2}$ no sistema, que poderia induzir a atividade bacteriana nesse meio.

As variações de $\mathrm{pH}$ observadas também foram pouco significa- 
tivas durante o período, o que confirma a estabilidade das amostras ao longo dos 3 anos. Portanto, amostras de sedimentos mantidas em condições controladas de luz, calor e ausência de $\mathrm{O}_{2}$ podem ser estocadas por um longo período, até serem analisadas. Vale ressaltar que as recomendações da $\mathrm{APHA}^{25}$ são para se evitar estocagem de amostras de ambientes impactados. No entanto, pelo menos em termos dos parâmetros avaliados, pode-se considerar que existe a possibilidade de se estocar amostras por longos períodos, desde que exista um controle sob o modo de preservação adotado.

\section{Estudo biogeoquímico dos sedimentos: sulfetos, matéria orgânica e granulometria}

Alguns parâmetros analíticos complementares em termos das características biogeoquímicas e suas possíveis associações aos metais pesados no ambiente do Rio Tietê foram também avaliados. Os resultados estão indicados na Tabela 1 .

Os valores de SVA mostraram-se bastante elevados na amostra do Reservatório de Pirapora, que foi da ordem de $14.425 \mu \mathrm{g} / \mathrm{g}$. Este valor está fortemente relacionado à elevada carga poluidora que se concentra neste ambiente e indica uma intensa anaerobiose e estagnação. A formação dos sulfetos se dá, principalmente, via mediação bacteriana, com redução química dos íons $\mathrm{SO}_{4}{ }^{2-}$ e é favorecida pela ausência de $\mathrm{O}_{2} \cdot{ }^{26}$

Após a Barragem de Pirapora, há uma sensível diminuição de SVA (cerca de 20 vezes) nas amostras de Rasgão e Tecelagem (reservatórios vizinhos no trecho a jusante), causada pela oxigenação na coluna d'água, que pode eventualmente afetar os sedimentos de fundo.

Os valores de SVA apresentaram-se ainda menores ao longo do curso do rio, devido a uma significativa diminuição da quantidade de efluentes lançados, além da distância da fonte antrópica principal, considerada como sendo o Reservatório de Pirapora. Os valores de SVA na entrada do Reservatório de Barra Bonita foram relativamente elevados $(104 \mu \mathrm{g} / \mathrm{g})$. Entretanto, no trecho intermediário e a jusante deste reservatório, os valores de SVA encontrados são típicos de ambientes óxidos e pouco impactados.

Segundo a classificação geoquímica apresentada por Berner, ${ }^{27} \mathrm{o}$ Reservatório de Pirapora, bem como todo o trecho de estudo, podem ser classificados como ambientes anóxidos e sulfídricos $\left(\mathrm{H}_{2} \mathrm{~S} \geq 10^{-6}\right.$ $\mathrm{M})$. Por outro lado, o Reservatório de Barra Bonita pode ser classificado como um ambiente não-sulfídrico e pós-óxido $\left(\mathrm{H}_{2} \mathrm{~S}<10^{-6} \mathrm{M}\right)$, não devendo apresentar níveis elevados de sulfetos e matéria orgânica, que é concordante com os resultados da extração seqüencial.

Uma importante correlação foi verificada entre os valores de $\mathrm{E}_{\mathrm{H}}$ e de log SVA $(0,9979)$ para os 4 primeiros pontos amostrais, desde Pirapora até a entrada de Barra Bonita. A correlação entre $\mathrm{E}_{\mathrm{H}}$ e $\mathrm{pS}$ ocorreu somente no trecho onde a concentração de SVA foi muito elevada. Ao se incluir os pontos correspondentes ao Reservatório de Barra Bonita, verifica-se um valor muito mais baixo $(0,5168)$, demonstrando assim que o controle do $\mathrm{E}_{\mathrm{H}}$ não é mais dado por esta espécie química, mas por uma somatória de potenciais de outras espécies, além do efeito de potenciais desnecessários apontados por Whitfield, ${ }^{24}$ que não representam os valores de espécies químicas em equilíbrio.

Embora as curvas $\mathrm{E}_{\mathrm{H}} \mathrm{x} \mathrm{pS}$ tenham sido estudadas principalmente com relação ao comportamento eletroquímico do par $\mathrm{S}^{2-} / \mathrm{S}^{0}$, sabe-se que este sistema não é termodinamicamente reversível. A resposta apresentada pelo eletrodo de platina é, na realidade, dada pelo par $\mathrm{S}_{\mathrm{n}}^{2-/ \mathrm{S}^{0}}$, termodinamicamente reversível. Isto explica a correlação verificada somente no trecho mais contaminado, entre os reservatórios de Pirapora e Barra Bonita, devido à presença de $\mathrm{S}^{0} \mathrm{e}$, conseqüentemente, de polissulfetos, cuja formação é sugerida a partir das seguintes reações: ${ }^{28}$

$$
\begin{aligned}
& \mathrm{Fe}^{3+}{ }_{(\mathrm{aq})}+\mathrm{H}_{2} \mathrm{~S}_{(\mathrm{aq})} \rightarrow \mathrm{Fe}^{2+}{ }_{(\mathrm{aq})}+\mathrm{S}_{(\mathrm{s})}^{0}+2 \mathrm{H}^{+} \\
& \mathrm{Fe}(\mathrm{OH})_{3(\mathrm{~s})}+3 \mathrm{H}_{2} \mathrm{~S}_{(\mathrm{aq})} \rightarrow 2 \mathrm{FeS}_{(\mathrm{s})}+\mathrm{S}_{(\mathrm{s})}^{0}+6 \mathrm{H}_{2} \mathrm{O}
\end{aligned}
$$

A Equação 1 representa a redução química dos íons $\mathrm{Fe}^{3+}$ e correspondente formação de $\mathrm{S}^{0}$, dada pela oxidação dos íons $\mathrm{S}^{2-}$. Em excesso de íons $S^{2-}$, esta reação prossegue e dá origem à formação de pirita $\left(\mathrm{FeS}_{2}\right)$. A Equação 2 representa a formação de troilita (FeS) em ambiente aquático, e também sugere a redução de $\mathrm{Fe}^{3+}$, embora na forma hidrolisada. $\mathrm{O}$ ambiente redutor de Pirapora favorece a formação dos complexos de polissulfetos, devido às elevadas concentrações de $\mathrm{S}^{2-} \mathrm{e}$ de $\mathrm{Fe}^{3+}$ (conforme resultados obtidos para os metais).

Nos pontos amostrais cujas concentrações de SVA foram baixas, o $E_{H}$ não se correlacionou com o SVA, justamente por não haver $S^{0}$ e, conseqüentemente, espécies de polissulfetos presentes. Dessa forma, pode-se considerar que no ambiente de Barra Bonita existe um outro mecanismo de controle de $\mathrm{E}_{\mathrm{H}}$, que não é dado pelas espécies de polissulfetos.

Estudos em amostras de ambientes estuarinos, ricos em sulfeto e matéria orgânica, devido à sua condição redutora natural, apresentaram correlação entre valores de $\mathrm{E}_{\mathrm{H}}$ e de $\mathrm{pS} .{ }^{24,29}$ No entanto, nestes trabalhos atribuiu-se de forma equivocada a dependência do $E_{H}$ às concentrações de íons $\mathrm{S}^{2-}$ livres, pois esses ambientes apresentam um intenso processo de piritização, dado pela elevada concentração de polissulfetos, que controlam o potencial redox do sistema, por se tratar de um sistema reversível.

Ainda com relação aos resultados da Tabela 1, foram verificados

Tabela 1. Resultados de $\mathrm{E}_{\mathrm{H}}$, SVA, carbono (total, inorgânico e orgânico) e granulometria de amostras de sedimentos do Rio Tietê. Valores de

\begin{tabular}{|c|c|c|c|c|c|c|c|c|}
\hline Amostra & $\mathrm{E}_{\mathrm{H}}^{* *}(\mathrm{mV})$ & SVA $(\mu \mathrm{g} / g)$ & $\mathrm{C}$ total $(\%)$ & $\mathrm{C}$ inorg. $(\%)$ & $\mathrm{C}$ org. $(\%)$ & $\begin{array}{c}\text { Fração } \\
<63 \mu \mathrm{m}(\%)\end{array}$ & $\begin{array}{c}\text { Fração } \\
<20 \mu \mathrm{m}(\%)\end{array}$ & $\begin{array}{c}\text { Umidade } \\
(\%)\end{array}$ \\
\hline Pirapora & -290 & 14.425 & 2,72 & 0,40 & 2,32 & 52 & 36 & 75,5 \\
\hline Rasgão & -206 & 633 & 3,22 & 0,72 & 2,50 & 40 & 23 & 63,7 \\
\hline Tecelagem & -199 & 615 & 2,10 & 0,87 & 1,23 & 69 & 8 & 48,9 \\
\hline Ponte R.Tietê-Capivari & -152 & 133 & 3,10 & 1,96 & 1,14 & 39 & 47 & 50,4 \\
\hline Entrada de Barra Bonita & -190 & 104 & 0,90 & 0,18 & 0,72 & 24 & 4 & 36,3 \\
\hline Jusante de Barra Bonita & -220 & 3,5 & 0,63 & 0,54 & 0,09 & 35 & 2 & 27,5 \\
\hline Ilha de Barra Bonita & +168 & $<0,03$ & 0,36 & 0,10 & 0,26 & 9 & 1 & 11,8 \\
\hline
\end{tabular}
SVA e frações granulométricas correspondem a triplicatas e, das frações de carbono, a duplicatas de análises*

* Os resultados apresentaram desvios inferiores a $10 \%$. ** A grandeza $\mathrm{E}_{\mathrm{H}}$ adotada neste trabalho refere-se ao valor lido versus $\mathrm{Ag} / \mathrm{AgCl}$.

Esta tem sido a forma mais usual de sua expressão. 
níveis de concentração significativos de carbono total, principalmente no trecho mais poluído, definido pelos Reservatórios de Pirapora, Rasgão e Tecelagem. Nestes ambientes também há predominância de carbono na fração orgânica, indicando que existe um elevado acúmulo de matéria orgânica de origem alóctone, pelo fato destes ambientes serem fortemente impactados por poluição de fontes difusas, especialmente de esgotos domésticos.

Os níveis de concentração de carbono total seguem o mesmo padrão verificado para as concentrações de SVA, mas não mostram uma correlação significativa com este parâmetro. Os menores valores de carbono total foram verificados em Barra Bonita, podendo ser indicativos de menor influência de cargas poluidoras neste ambiente.

Os resultados das análises granulométricas mostraram elevadas frações de silte e argila $(<63 \mu \mathrm{m})$, que é consistente com o fato de terem sido obtidas amostras nas regiões mais profundas dos ambientes estudados, uma vez que os sedimentos de granulação fina se acumulam em zonas mais profundas de ambientes aquáticos. A presença de matéria orgânica oriunda de cargas poluidoras e as concentrações mais elevadas de metais pesados também corroboram com as maiores proporções de sedimentos de granulação fina. As amostras de sedimentos do Reservatório de Pirapora apresentaram quase $90 \%$ de frações granulométricas mais finas e, nos outros pontos de amostragem até a Ponte do Rio Tietê-Capivari, também se observaram elevados valores para estas frações, justificando uma potencial participação dos sedimentos de fundo em contato com a coluna d'água, que é dado pela reatividade dos mesmos nos processos sólido-solução.

\section{Extração seqüencial de metais}

O estudo referente à extração seqüencial de metais pesados foi realizado em dois importantes ambientes sob o ponto de vista de contaminação do Rio Tietê: Reservatórios de Pirapora e de Barra Bonita (amostras obtidas na entrada destes reservatórios). Tal escolha foi baseada nas considerações de Eysink et al. ${ }^{30}$ que sugeriram estar havendo uma significativa contaminação em Barra Bonita proveniente da Região Metropolitana de São Paulo. Os resultados referentes às amostras de Pirapora e de Barra Bonita estão representados nas Figuras 3 e 4, respectivamente.

Pode-se verificar que, para todos os metais estudados, somente $\mathrm{Ni}$ e $\mathrm{Zn}$ se distribuíram em todas as frações determinadas nas amostras de Pirapora, inclusive nas mais lábeis (trocáveis e carbonatos). Tais resultados concordam com as observações de Gupta e Chen, ${ }^{31}$ que ao estudarem a distribuição desses mesmos metais em sedimentos, verificaram que há uma diminuição percentual na seguinte ordem: $\mathrm{Zn}>\mathrm{Ni}>\mathrm{Cr}>\mathrm{Pb}>\mathrm{Cd}>\mathrm{Cu}$.

Kersten e Förstner, ${ }^{5,8}$ ao estudarem sedimentos do Rio Elba, encontraram valores menores que $0,1 \%$ para os referidos metais no primeiro extrato, que são parcialmente concordantes com os resultados obtidos neste trabalho. Ainda com relação às formas lábeis, pode-se verificar que alguns metais, como $\mathrm{Cd}, \mathrm{Zn}$ e Ni, apareceram na fração facilmente redutível em percentuais significativos (42, 23 e $20 \%$, respectivamente). A distribuição dos metais na fração moderadamente redutível (4 etapa), que é considerada não lábil devido à interação dos metais com óxidos amorfos presentes nas amostras de sedimentos de Pirapora, foi na seguinte ordem crescente: $\mathrm{Cr}>\mathrm{Zn}>\mathrm{Pb}>\mathrm{Ni}>\mathrm{Cd}>\mathrm{Cu}$.

A extração correspondente à fração de sulfetos e matéria orgânica mostrou que os metais se distribuíram nos seguintes valores percentuais: $\mathrm{Pb}(50 \%), \mathrm{Cd}(43 \%), \mathrm{Cu}(65 \%), \mathrm{Cr}(42 \%), \mathrm{Zn}(29 \%)$ e $\mathrm{Ni}(10 \%)$. Os elevados valores de SVA e de matéria orgânica encontrados nas amostras de sedimentos de Pirapora justificam os resultados verificados principalmente para $\mathrm{Pb}$ e Cd. Além disso, metais como $\mathrm{Cu}$ e $\mathrm{Pb}$ apresentam forte interação com a matéria orgânica por adsorção e,
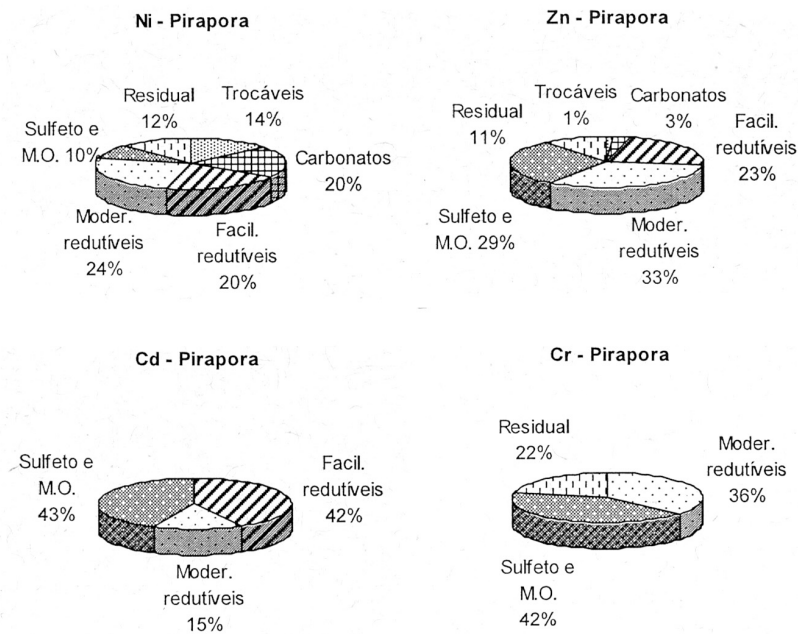

Cr - Pirapora
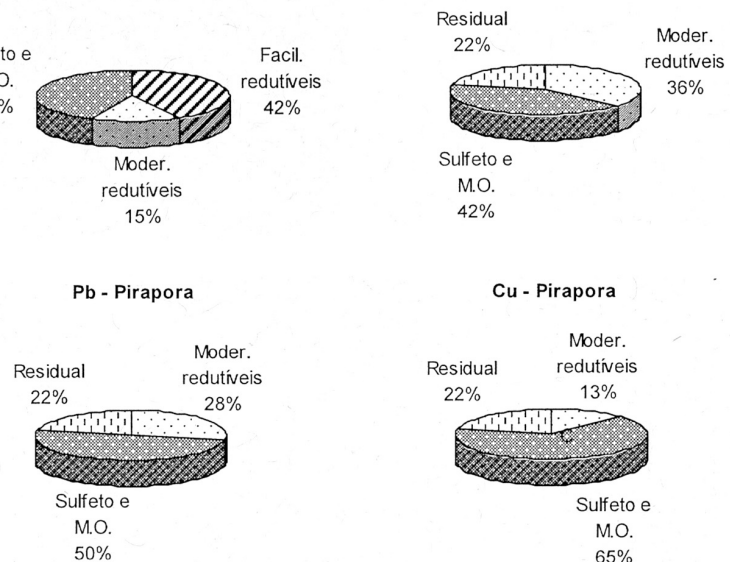

$42 \%$

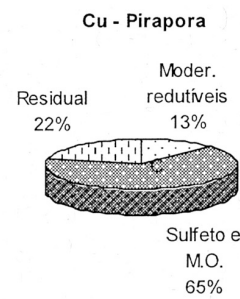

Figura 3. Distribuição dos metais pesados nas diversas fases do sedimento da amostra de Pirapora, segundo o método de extração seqüencial adotado. Os resultados foram obtidos através de média de triplicatas, com desvios variando entre 8,3 e 47,0\%, sendo estes atribuídos aos procedimentos de obtenção dos extratos

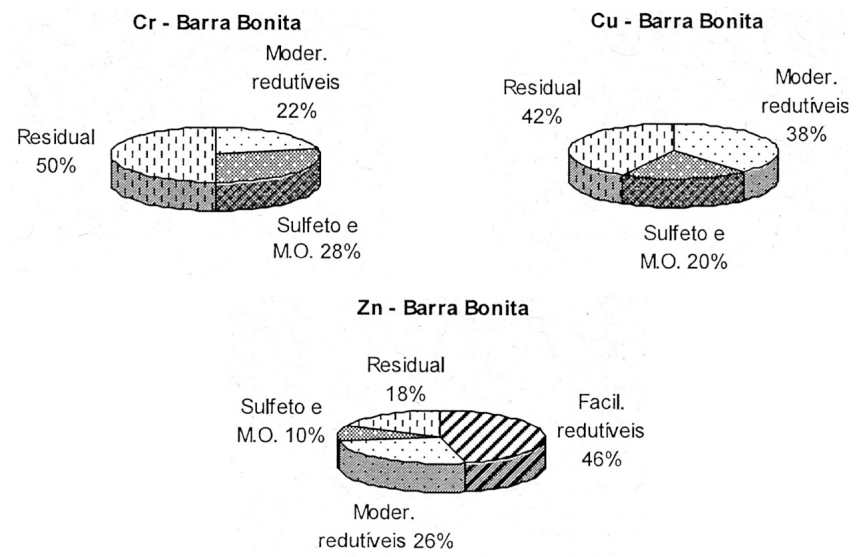

Figura 4. Distribuição dos metais pesados nas diversas fases do sedimento da amostra de Barra Bonita, segundo o método de extração seqüencial adotado. Os resultados foram obtidos através de média de triplicatas, com desvios variando entre 4,3 e 39,0\%, sendo estes atribuídos aos procedimentos de obtenção dos extratos

principalmente por complexação, formando humato-complexos nas condições verificadas. ${ }^{32} \mathrm{~A}$ forte contribuição dos sulfetos, e como se postula neste trabalho, polissulfetos, esclarecem a significativa participação dos metais nesta fase. No caso do Cr, uma provável formação de hidróxido e posterior co-precipitação propiciam o elevado valor verificado para este metal.

Embora a fração de sulfetos e matéria orgânica seja considerada inerte para o método analítico adotado, sabe-se que os valores encontrados para sulfetos e, por consequiência, complexos de polissulfetos podem possibilitar uma significativa solubilização dos metais aumen- 
tando a sua mobilização em oposição à baixa solubilidade esperada para esta respectiva fração. A condição sulfídrica encontrada no Rio Tietê na região de Pirapora possibilita considerar-se a existência de complexos solúveis de polissulfetos dos metais na própria coluna d'água, o que favorece a disponibilidade destes metais à biota aquática.

Em relação à amostra de sedimento do Reservatório de Barra Bonita, verifica-se que $\mathrm{Pb}, \mathrm{Cd}$ e Ni não foram encontrados nos extratos, dentro dos níveis de determinação do método analítico $(<0,1 \%)$ para todas as frações determinadas. Em função disso, somente $\mathrm{Cu}, \mathrm{Cr}$ e Zn puderam ser determinados.

A fração facilmente redutível foi determinada somente para $\mathrm{Zn}$. Os resultados da fração correspondente a sulfetos e matéria orgânica foram bem menores na amostra de Barra Bonita em relação aos valores observados em Pirapora, devido à menor ação antrópica observada neste reservatório. Estes resultados são confirmados pelos valores obtidos na fração residual: $\mathrm{Cr}(50 \%), \mathrm{Cu}(42 \%)$ e, em menor extensão, Zn (18\%). Embora a fração residual não tenha importância dentro dos processos diagenéticos recentes, por se tratarem de formações litogênicas, sendo considerada inerte, ela auxilia significativamente na interpretação dos resultados de extração seqüencial. ${ }^{4,5,8}$ Os baixos valores verificados para esta fração na amostra de Pirapora confirmam a forte influência de fontes poluidoras alóctones que se acumulam nos sedimentos de fundo. Por outro lado, os resultados obtidos para a amostra de sedimentos do Reservatório de Barra Bonita indicaram valores típicos de um ambiente pouco impactado.

Portanto, com base nas determinações realizadas, pode-se dizer que o Reservatório de Barra Bonita vem sofrendo influência antrópica da região de Pirapora do Bom Jesus; entretanto, existem condições naturais neste ambiente que favorecem os efeitos de diluição de cargas poluidoras, seja pelo maior volume de água ou por mecanismos locais de assoreamento.

\section{Extração de metais com $\mathrm{HCl} 0,1 \mathrm{~mol} \mathrm{~L}^{-1}$ e abertura total}

Foram realizadas extrações a frio em meio de $\mathrm{HCl} 0,1 \mathrm{~mol} \mathrm{~L}^{-1}$ e aberturas totais nas mesmas amostras que foram submetidas à extração seqüencial. Os resultados analíticos obtidos para os metais determinados estão nas Tabelas 2 e 3.

Comparando-se os resultados obtidos para as concentrações totais com os valores de referência do folhelho médio, que é utilizado para caracterizar contaminação em sedimentos, pode-se verificar que a amostra do Reservatório de Pirapora apresentou valores muito superiores para todos os metais determinados. ${ }^{33}$ Os valores mais significativos foram encontrados para $\mathrm{Cd}, \mathrm{Pb}$ e $\mathrm{Zn}$; sendo 25, 13 e 6 vezes superiores ao folhelho médio, respectivamente. No caso da amostra do Reservatório de Barra Bonita, os valores de concentração total foram semelhantes aos do folhelho médio, com exceção do $\mathrm{Cd}$, o que é concordante com os resultados obtidos por Silva et al. ${ }^{34}$

Os resultados obtidos para a extração em meio de $\mathrm{HCl} 0,1 \mathrm{~mol} \mathrm{~L}^{-1}$ e os respectivos potenciais biodisponíveis mostraram que quando os sedimentos do Reservatório de Pirapora são submetidos a condições de oxidação (representadas pela secagem da amostra) ocorre uma considerável liberação (labilidade) destes metais para a solução, especialmente Ni $(81,2 \%)$, Mn (81,4\%), Cu (72,5\%) e Cd (54,0\%). A amostra de sedimento do Reservatório de Barra Bonita apresentou um comportamento bastante diferenciado em relação à Pirapora, sendo que houve uma maior liberação de $\mathrm{Mn}(100,0 \%), \mathrm{Cu}(44,0 \%)$ e $\mathrm{Zn}(42,8 \%)$.

Neste procedimento de extração deve-se considerar também a possibilidade de solubilização de polissulfetos, em meio ácido, diluído. A presença dos complexos de polissulfetos dos metais, exceto Cr, é reforçada pela elevada concentração de SVA na amostra de Pirapora, sendo os mecanismos prováveis de formação aqueles apresentados nas Equações 1 e 2. Caso houvesse a presença de sulfetos dos metais, tais como os de $\mathrm{Cd}$, $\mathrm{Ni}$ e $\mathrm{Pb}$, ao invés dos polissulfetos, certamente estes não solubilizariam em meio $\mathrm{HCl}$ diluído, o que se opõe ao verificado experimentalmente para essa amostra. Com, isto, reforça-se a existência de polissulfetos entre os Reservatórios de Pirapora e de Barra Bonita.

Alguns estudos complementares foram realizados com a amostra de Pirapora em meio de $\mathrm{HCl}$ 0,1 e $2 \mathrm{~mol} \mathrm{~L}^{-1}$ a quente, determinando-se os metais $\mathrm{Cd}, \mathrm{Cu}$ e $\mathrm{Pb}$. Os resultados mostraram que nestas condições, uma significativa quantidade dos metais precipitou devido à decomposição dos polissulfetos, formando $\mathrm{H}_{2} \mathrm{~S}$, segundo as reações:

$\mathrm{H}_{2} \mathrm{~S}+\mathrm{S}^{0} \rightarrow \mathrm{H}_{2} \mathrm{~S}_{\mathrm{n}}$

Tabela 2. Resultados obtidos para extração com $\mathrm{HCl} 0,1 \mathrm{~mol} \mathrm{~L}^{-1}(\mu \mathrm{g} / \mathrm{g})$, abertura total $(\mu \mathrm{g} / \mathrm{g})$ e potencial biodisponível (\%) para a amostra do Reservatório de Pirapora

\begin{tabular}{lcccccccc}
\hline & $\mathrm{Cu}$ & $\mathrm{Cd}$ & $\mathrm{Cr}$ & $\mathrm{Pb}$ & $\mathrm{Ni}$ & $\mathrm{Zn}$ & $\mathrm{Fe}$ & $\mathrm{Mn}$ \\
\hline Extração com HCl 0,1 mol L-1* & 121,0 & 4,0 & 44,0 & 61,0 & 105,5 & 147,0 & 13.700 & 136,0 \\
Abertura total & & & & & & & & \\
(HNO $\left._{3} / \mathrm{HCl} / \mathrm{HF}\right)^{*}$ & 167,0 & 7,4 & 206,0 & 259,0 & 130,0 & 573,0 & 63.000 & 167,0 \\
Potencial biodisponível (\%)** & 72,5 & 54,0 & 21,4 & 23,6 & 81,2 & 25,6 & 21,7 & 81,4 \\
\hline
\end{tabular}

* Resultados correspondentes a triplicatas de análises, cujos desvios foram inferiores a $15 \%$. ** Potencial biodisponível foi definido neste trabalho como a razão entre os resultados de extração com $\mathrm{HCl} 0,1 \mathrm{~mol} \mathrm{~L}^{-1}$ e os de abertura total.

Tabela 3. Resultados obtidos para extração com $\mathrm{HCl} 0,1 \mathrm{~mol} \mathrm{~L}^{-1}(\mu \mathrm{g} / \mathrm{g})$, abertura total $(\mu \mathrm{g} / \mathrm{g})$ e potencial biodisponível (\%) para a amostra da entrada do Reservatório de Barra Bonita

\begin{tabular}{lcccccccc}
\hline & $\mathrm{Cu}$ & $\mathrm{Cd}$ & $\mathrm{Cr}$ & $\mathrm{Pb}$ & $\mathrm{Ni}$ & $\mathrm{Zn}$ & $\mathrm{Fe}$ & $\mathrm{Mn}$ \\
\hline $\begin{array}{l}\text { Extração com HCl 0,1 mol.L-1* } \\
\text { Abertura total }\end{array}$ & 5,2 & $<0,05$ & 2,4 & 4,5 & 5,8 & 10,7 & 10.100 & 412,0 \\
(HNO $_{3}$ / HCl / HF)* & 12,0 & 1,8 & 8,0 & 25,0 & 60,0 & 25,0 & 40.000 & 412,0 \\
Potencial biodisponível (\%)** & 44,2 & $<2,8$ & 30,0 & 18,0 & 9,7 & 42,8 & 25,3 & 100,0 \\
\hline
\end{tabular}

* Resultados correspondentes a triplicatas de análises, cujos desvios foram inferiores a $15 \%$. ** Potencial biodisponível foi definido neste trabalho como a razão entre os resultados de extração com $\mathrm{HCl} 0,1 \mathrm{~mol} \mathrm{~L}^{-1}$ e os de abertura total. 
$\mathrm{H}_{2} \mathrm{~S}_{\mathrm{n}} \rightarrow \mathrm{H}_{2} \mathrm{~S}+\mathrm{S}^{0}$

$\mathrm{M}^{\mathrm{n}+}+\mathrm{H}_{2} \mathrm{~S} \rightarrow \mathrm{M}_{2} \mathrm{~S}_{\mathrm{n}}$

Com isso, confirmou-se experimentalmente a presença dos polissulfetos na amostra de Pirapora e, conseqüentemente, até a entrada do Reservatório de Barra Bonita, o que conduz a um importante modelo de interpretação biogeoquímica dos sedimentos do Rio Tietê.

\section{CONCLUSÃO}

Os resultados obtidos na determinação da estabilidade das amostras permitem considerar-se que amostras obtidas em ambientes tipicamente impactados, como as do Rio Tietê, desde que mantidas sob um rigoroso cuidado, como ausência de luz e calor, podem manter suas características originais de amostragem em termos de parâmetros como $\mathrm{pH}$ e $\mathrm{E}_{\mathrm{H}}$.

As determinações do potencial redox em amostras de sedimentos mostraram que o ambiente do Tietê desde o Reservatório de Pirapora até a entrada de Barra Bonita é predominantemente anóxido, dominado por condições de estagnação e anaerobiose, onde há um elevado acúmulo de matéria orgânica de origem alóctone, pelo fato destes ambientes serem fortemente impactados por poluição de fontes difusas, especialmente de esgotos domésticos advindos da Região Metropolitana de São Paulo.

Os resultados obtidos para SVA também revelaram que as condições verificadas em Pirapora são de um regime anóxido e sulfídrico, enquanto que no interior do Reservatório de Barra Bonita predomina um regime pós-óxido e não-sulfídrico. As relações verificadas entre $E_{H}$ e pSVA indicaram que o potencial redox é controlado por espécies reversíveis, como o par $\mathrm{S}_{\mathrm{n}}{ }^{2-} / \mathrm{S}^{0}$, importantes na especiação dos metais nos sedimentos.

As determinações dos metais pesados mostraram que em Pirapora há uma significativa contaminação, com elevados potenciais de biodisponibilidade, estimados através de extrações a frio em meio de $\mathrm{HCl} \mathrm{0,1} \mathrm{mol} \mathrm{L}^{-1}$, corroborados em parte pelo método de extração seqüencial, especialmente para $\mathrm{Ni}, \mathrm{Mn}, \mathrm{Cu}$ e $\mathrm{Cd}$; enquanto que no caso da amostra do Reservatório de Barra Bonita, os resultados indicaram haver uma contaminação significativa para $\mathrm{Cd}$, com elevados potenciais de biodisponibilidade para $\mathrm{Mn}, \mathrm{Cu}$ e $\mathrm{Zn}$.

O método de extração seqüencial adotado indicou que na amostra de Pirapora, os metais $\mathrm{Cd}, \mathrm{Cr}, \mathrm{Cu}$ e $\mathrm{Pb}$ estão associados preferencialmente às frações facilmente redutível, moderadamente redutível, sulfetos e matéria orgânica e residual, ou seja, aquelas consideradas menos lábeis do sedimento, exceto para Ni e Zn. Este comportamento foi semelhante para a amostra do Reservatório de Barra Bonita, no caso dos metais $\mathrm{Cr}$, $\mathrm{Cu}$ e $\mathrm{Zn}$.

A análise granulométrica indicou a presença dominante das frações silte e argila nos sedimentos mais contaminados, o que sugere uma participação intensa dos sedimentos de Pirapora na redistribuição dos metais para a coluna d'água.

Com relação aos resultados até certo ponto preocupantes sobre a presença de polissulfetos e conseqüente complexação e solubilização dos metais em Pirapora, parece ser evidente que um ambiente rico em sulfetos não representa necessariamente um sumidouro de metais, mas um ambiente potencialmente reativo dessas espécies tóxicas e sujeitas à remobilização. Nesse sentido, novos estudos levando-se em conta variações temporais e sazonais podem proporcionar um maior conhecimento das ciclagens óxidas e anóxidas e, por conseqüência, avaliar-se a intensidade de remobilização dessas espécies.

\section{AGRADECIMENTOS}

Ao CNPq pelo suporte financeiro e à CETESB, pelo apoio nos trabalhos de campo.

\section{REFERÊNCIAS}

1. Mortimer, C. H.; J. Ecol. 1941, 29, 280; Mortimer, C. H.; J. Ecol. 1942, 30, 147; Hutchinson, G. E.; Wollack, A.; Setlow, J. K.; Am. J. Sci. 1943, 241, 533.

2. Mudrock, A.; MacKnight, S. D.; CRC Handbook of Techniques for Aquatic Sediments Sampling, CRC Press: Boca Raton, 1991.

3. Salomons, W.; Förstner, U.; Metals in the Hydrocycle, Springer-Verlag: Berlin, 1984.

4. Kersten, M.; Förstner, U.; Water Sci. Technol. 1986, 18, 121.

5. Kersten, M.; Förstner, U.; Mar. Chem. 1987, 22, 299.

6. Kheboian, C; Bauer, C. F.; Anal. Chem. 1987, 59, 1417.

7. Quevauviller, P.; Rauret, G.; Griepink, B.; Int. J. Environ. Anal. Chem. 1993, 51, 231

8. Kersten, M.; Förstner, U. Em Trace Element Speciation: Analytical Methods and Problems; Batley, G. E., ed.; CRC Press: Boca Raton, 1989.

9. Campbell, P. G. C.; Carignan, R.; Biologically Available Metals in Sediments, NRCC Report, 27694, Ottawa, 1988.

10. EPA-ROC; The Standard Methods for the Determination of Heavy Metals in Soils, National Institute of Environmental Analysis: Taipei, 1991.

11. Luoma, S. N.; Bryan, G. W.; Sci. Total Environ. 1981, 17, 165

12. Luoma, S. N.; Sci. Total Environ. 1983, 28, 1.

13. Pickering, W. F.; Ore Geology 1986, 1, 83.

14. Silvério, P. F.; Fonseca, A. L.; Botta-Paschoal, C. M. R.; Mozeto, A. A.; Aquatic Ecosys. Health Manag. 2005, 8, 1.

15. Bevilacqua, J. E.; Tese de Doutorado, Universidade de São Paulo, Brasil, 1996.

16. ZoBell, C. E.; Am. Assoc. Petrol. Geol. 1946, 30, 447.

17. Christian, G.; Instrumental Analysis, John Wiley and Sons: New York, 1994.

18. Orion Research Incorporated; Applications Bulletin, 1969, no. 12, Determination of total sulfide content in water.

19. Cornwell, J. C.; Morse, J. W.; Mar. Chem. 1987, 22, 193.

20. Baumann, E. W.; Anal. Chem. 1974, 46, 1345.

21. Serrano, S. H. P.; Tese de Doutorado, Universidade de São Paulo, Brasil, 1988.

22. Ackermann, F.; Bergmann, H.; Schleichert, U.; Environ. Technol. Lett. $\mathbf{1 9 8 3}, 4,317$.

23. Wood, W. W.; Guidelines for collection and field analysis of groundwater samples for selected unstable constituents, United States Geological Survey: Washington, 1976.

24. Whitfield, M.; Limnol. Oceanogr. 1969, 14, 547.

25. American Public Health Association - APHA; Standard Methods for the Examination of Water and Wastewater, $17^{\text {th }}$ ed., Washington, DC, 1989.

26. Stumm, W.; Morgan, J. J.; Aquatic Chemistry, Wiley Interscience: USA, 1970.

27. Berner, R. A.; J. Sed. Petrol. 1981, 51, 359.

28. Morse, J. W.; Millero, F. J.; Cornwell, J. C.; Rickard, D.; Earth Sci. Rev. 1987, 24, 1; O'neill, P.; Environmental Chemistry, $2^{\text {nd }}$ ed., Chapman \& Hall: Londres, 1994.

29. Berner, R. A.; Geochim. Cosmochim. Acta 1963, 27, 563.

30. Eysink, G. J. G.; Hatamura, E.; Nakasaki, A.; Bruni, A. C.; Reis, M. S. P.; Moraes, R. P.; $6^{\text {th }}$ International Conference on the Conservation and Management of Lakes, Kasumigaura, Japão, 1995.

31. Gupta, S. K.; Chen, K. Y.; Environ. Technol. Lett. 1975, 10, 129.

32. Jackson, T. A.; Environ. Geol. 1978, 2, 173.

33. Förstner, U. Em Interactions between Sediments and Freshwater; Göltermen, H. L., ed.; The Hague 1977, p. 94.

34. Silva, I. S.; Abate, G.; Lichtig, J.; Masini, J. C.; Appl. Geochem. 2002, $17,105$. 